Psychological Medicine, 1988, 18, 793-797

Printed in Great Britain

EDITORIAL

\title{
Post-mortem neurochemistry of schizophrenia ${ }^{1}$
}

There is little doubt that brain tissue taken at autopsy has provided a valuable means to investigate the various neurochemical hypotheses of schizophrenia. This approach to the study of neurological and psychiatric disease has received increasing attention over the past three decades as its potential has become recognized. The observation that dopamine was severely depleted in the striatum of Parkinson's disease patients led directly to the initial trial of the highly successful L-dopa therapy. More recently, important if less dramatic advances in our understanding of Huntington's disease and senile dementia have been gained from post-mortem studies. However, the search for a biochemical abnormality in schizophrenia has classically involved the analysis of body fluids. These studies have been disappointing; the literature on the biochemistry of schizophrenia is littered with inconsistent findings and artefactual results. Two notable examples are the story of the endogenous psychotogenic 'pink spot' and investigations of platelet monoamine oxidase, each of which was founded on insecure premises and consumed many man-years of research effort in the pursuit of artefactual results.

It was the search for endogenous psychotogens which first focused interest on tryptophan metabolism and 5-hydroxytryptamine (5HT) function. Studies of post-mortem brain tissue from schizophrenic patients have, however, provided no indication of abnormalities in concentrations of tryptophan metabolites in either the 5HT or kynurenine pathways (Joseph et al. 1979). Reports of a decrease in frontal cortical 5HT-2 receptors, as measured using the binding of radiolabelled LSD to a cell membrane preparation from post-mortem tissue (Bennett et al. 1979), renewed interest in 5HT function in schizophrenia, but no confirmation of these findings resulted from further studies employing LSD (Whitaker et al. 1981) or the more specific ligand, ketanserin (Reynolds et al. 1983).

The possibility of abnormal noradrenergic function in schizophrenia was originally proposed by Stein \& Wise (1971) after consideration of the role of noradrenergic pathways in reward mechanisms in animals, and finding a reduced activity of dopamine $\beta$-hydroxylase (the specific synthetic enzyme for noradrenaline) in various brain regions, including the brainstem, in schizophrenic patients (Wise \& Stein, 1973). Further studies were unable to repeat this finding (Crow et al. 1981). Nevertheless, the hypothesis was modified and developed by Hornykiewicz (1982) on the basis of an increase in noradrenaline concentrations in the nucleus accumbens in schizophrenia (Farley et al. 1978). Again, however, other groups could not repeat these results, although an increase in the noradrenergic metabolite, MHPG, in this region has been reported (Kleinman et al. 1981). There has been criticism of this evidence for the involvement of noradrenaline in schizophrenia (Iversen et al. 1983), and the influence of neuroleptic medication on the postmortem findings has not been excluded.

It is the common action of the antipsychotic drugs in blocking dopamine neurotransmission which has enabled the 'dopamine hypothesis' to remain the major theory of schizophrenic aetiology. In investigating whether there is a hyperactivity of dopamine function in schizophrenia, much effort has been expended measuring concentrations of the transmitter, its metabolites and associated enzymes in post-mortem brain tissue, albeit with few conclusive results. Recently, attention has focused on a more consistently reported finding. Since the first report (Owen et al. 1978) there has been substantial confirmation that dopamine D2 receptors are increased above control values in

\footnotetext{
1 Address for correspondence: Dr Gavin P. Reynolds, Department of Pathology, University of Nottingham Medical School, Queen's Medical Centre, Nottingham NG7 2UH.
} 
striatal brain regions from schizophrenic patients (Mackay et al. 1982; Reynolds et al. 1981; Seeman et al. 1984).

However, animal studies have shown that dopamine receptors increase in number after chronic neuroleptic administration (Clow et al. 1980), a treatment that most schizophrenics inevitably receive. Thus, it seems quite possible that medication is responsible for these findings. The original publications refute this, identifying one or two unmedicated patients who also have increased numbers of these D2 receptors. On the other hand, there are now several reports showing no increase in small groups of unmedicated patients (Mackay et al. 1982; Reynolds et al. 1981). As yet, in vivo imaging of radioactive ligands specific for these receptor sites has not provided an unequivocal conclusion and it still remains a point of considerable controversy whether the increase in receptors in post-mortem brain tissue bears any relation to the disease process per se.

The D1 subgroup of dopamine receptors is not thought to mediate directly the antipsychotic effects of the neuroleptic drugs. However, an increasing interest is being shown in drugs which act at these sites since they may function as enablers for D2 receptor activity. D1 receptor function in post-mortem brain, as measured by agonist-induced increase in the 'second messenger', adenylate cyclase, is not reportedly changed in schizophrenic patients. The density of D1 receptors as measured by the specific D1 antagonist SCH 23390 (Pimoule et al. 1985) is also unchanged in the putamen, and while a recent study found a drop in maximum binding of SCH 23390 in the caudate nucleus in schizophrenia (Hess et al. 1987), we were unable to confirm this observation of reduced D1 receptors (Reynolds \& Czudek, unpublished). However, there have been reports indicating abnormalities of function of these receptors in the schizophrenic brain. Using agents which by-pass the D1 recognition site and act directly on the adenylate cyclase activation system, an increase in cyclase stimulation in brain tissue has been observed in schizophrenia (Memo et al. 1983). This finding has been interpreted as indicating a possible facilitation of the coupling between the D1 dopamine recognition site and the 'effector' adenylate cyclase system. As yet, DI receptors have not been studied outside the striatal and accumbens nuclei although, unlike D2 receptors, they are present in significant quantities in some cortical and limbic nuclei.

One major advantage that post-mortem studies have is that the approach does let us concentrate on regions of the brain which are particularly likely to be involved in the production of schizophrenic symptoms and which include limbic structures, such as the hippocampus and amygdala, and the frontal and temporal cortices. Although cases have been made for the possible involvement of the ventral caudate and accumbens nuclei in psychiatric disease, evidence is still very tenuous and the dopamine-rich regions of the midbrain are thought to be concerned primarily with control of motor function. Surprisingly, the dopamine innervation of the limbic and cortical brain regions has been little studied. Dopamine receptor density (at least in respect of the neurolepticsensitive D2 receptor) in these areas is barely detectable, and few changes in other measures of dopamine function have been consistently observed.

Some findings do, however, provide further evidence for the involvement of dopamine in schizophrenia. Increased concentrations of homovanillic acid (HVA, the major dopamine metabolite) are found in cortical tissue from neuroleptic-treated (but not drug-free) patients (Bacopoulos et al. 1979). This is thought to be analogous to the effects of neuroleptic administration to animals, in which an initial increase in HVA eventually reverts to normal in most regions, although this tolerance does not develop in the frontal cortex (Bacopoulos et al. 1978). While this implicates the cortex in antipsychotic mechanisms, no inherent neurotransmitter change has been identified which might correlate with a primary cortical dysfunction in schizophrenia.

There is one intriguing neurochemical abnormality of the limbic system in schizophrenia. An increase in dopamine in the amygdala has been identified (Reynolds, 1983) which is restricted to the left hemisphere, the right amygdala showing no such increase above normal values. This highly specific neurochemical asymmetry of the brain in schizophrenia is not reflected by changes in a number of other transmitter markers studied, other than HVA; nor does it occur in other brain regions (Reynolds, 1987). This asymmetry provides the first neurochemical correlate of the substantial accumulation of evidence implicating schizophrenia as a dysfunction of the left temporal 
lobe, an hypothesis which was developed from the original observation of an association between left-sided temporal lobe epilepsy and schizophreniform symptoms (Flor-Henry, 1969). It is unclear whether this amygdala dopamine asymmetry relates to an asymmetry of dopaminergic innervation or to a relative change in dopamine function. This could be a response to unilateral neuronal atrophy of another neuronal system, although again the effects of drug treatment cannot yet be ruled out. The identification of an asymmetrical response to neuroleptics would be an interesting finding in itself.

It may be that there is such a response in the increase in dopamine receptors. We have found that normal subjects have an asymmetry of D2 receptors in the putamen which is accentuated in schizophrenia to an increase of approximately $20 \%$ in the right hemisphere (Reynolds et al. 1987). Whether or not neuroleptic treatment is responsible, this finding may well relate to the occurrence of asymmetries of movement in schizophrenia (e.g. Bracha, 1987).

The close relationship between the dopaminergic systems and neurones containing $\gamma$ aminobutyric acid (GABA) has led to the proposal that a reduction in the activity of this inhibitory neurotransmitter may underlie enhanced dopaminergic function in schizophrenia. However, there is no post-mortem evidence to support this hypothesis. An initial finding of decreased activity of glutamate decarboxylase (the GABA synthesizing enzyme) was subsequently found to be an artefact of differences in agonal state between the schizophrenic and control groups (Bird et al. 1978). Concentrations of GABA have also been found to be normal (Cross et al. 1979) and although neuroleptic treatment of animals increases nigral GABA binding, these and other GABA-related receptors are reportedly normal in schizophrenia (Crow et al. 1981; Czudek \& Reynolds, 1987).

Neuropeptides represent an area of neuroscience which has expanded rapidly in the past few years. Opiate peptides have been proposed as aetiological factors in schizophrenia and des-tyrendorphin has been reported as an antipsychotic, although this is disputed (Emrich et al. 1980). However, there is little post-mortem evidence implicating opiate peptides in schizophrenia. Metenkephalin is unchanged in several brain regions from a range of psychotic patients, although it was found to be diminished in a subgroup of chronic paranoid schizophrenics (Kleinman et al. 1983). A preliminary study (Carruthers et al. 1984) indicated a loss of met-enkephalin in the amygdala, although both these observations may be related to the effects of chronic neuroleptic drug treatment.

Other neuropeptides are changed in brain tissue in schizophrenia. Cholecystokinin (CCK) has been found to be reduced in temporal lobe structures of patients presenting with negative symptoms (Ferrier et al. 1983). Since CCK is closely implicated in the control of some mesolimbic dopamine neurones, these findings deserve further study. Ferrier et al. (1983) also find hippocampal somatostatin to be reduced in association with negative symptoms in schizophrenia, it being argued that these changes are probably unrelated to neuroleptic drug treatment. Few consistent changes in other neuropeptides have been reported. Neurotensin has been implicated in psychosis and antipsychotic drug action, particularly via its interaction with dopamine systems; yet after several studies there is no indication of an abnormality of neurotensin concentrations in the brain in schizophrenia (Bissette et al. 1986). Neurotensin receptors, on the other hand, are increased almost two-fold in the substantia nigra from neuroleptic treated schizophrenic patients, a finding which has been ascribed to the effects of drugs since neuroleptic administration to animals has an equivalent effect on neurotensin receptor density (Uhl \& Kuhar, 1984). The increase in vasoactive intestinal polypeptide in the amygdala in patients without negative symptoms (Roberts et al. 1983) is an intriguing finding which, like several of the other changes reported, may possibly reflect a process of neuronal dysfunction or loss within the temporal/limbic structures.

Indeed, there is morphological evidence supportive of such a degeneration. While it is outside the scope of this editorial to review the neuropathology of schizophrenia, mention can be made of the increased ventricular enlargement reported by many groups, and the gross atrophy (Brown $e t$ al. 1986) and neuronal disorganization (Jacob \& Beckmann, 1986) apparent in some areas of the temporal cortex. In some cases this appears lateralized, with more profound changes in the left hemisphere, observations which are consistent with many imaging studies and neuropsychological 
indices of laterality in schizophrenia. Along with the dopamine asymmetry and other chemical differences in limbic structures described above, these findings may well result from a neuroanatomical (and hence, almost inevitably, neuronal) disturbance. As yet, it is difficult to distinguish the post-mortem neurochemical correlates of neuronal disturbance in schizophrenia from the effects of prior drug treatment. Thus, it is becoming increasingly clear that only a concerted effort between neurochemical pathology, classical quantitative neuropathology and the modern in vivo neuropathology provided by imaging techniques, along with rigorous clinical assessment, will eventually permit us to approach a complete understanding of the biochemistry of schizophrenia.

GAVIN P. REYNOLDS

\section{REFERENCES}

Bacopoulos, N. G., Bustos, G., Redmond, D. E., Baulu, J. \& Roth, R. H. (1978). Regional sensitivity of primate brain dopaminergic neurons to haloperidol: alterations following chronic treatment. Brain Research 157, 396-401.

Bacopoulos, N. G., Spokes, E. G., Bird, E. D. \& Roth, R. H. (1979). Antipsychotic drug action in schizophrenic patients: effects on cortical dopamine metabolism after long-term treatment. Science 205, 1405-1407.

Bennett, J. P., Enna, S. J., Bylund, D. B., Gillin, J. C., Wyatt, R. J. \& Snyder, S. H. (1979). Neurotransmitter receptors in frontal cortex of schizophrenics. Archives of General Psychiatry 36, 927934.

Bird, E. D., Spokes, E. G. S., Barnes, J., Mackay, A. V. P., Iversen, L. L. \& Shepherd, M. (1978). Glutamic acid decarboxylase in schizophrenia. Lancet ii, 156.

Bissette, G., Nemeroff, C. B. \& Mackay, A. V. P. (1986). Peptides in schizophrenia. In Progress in Brain Research, vol. 66 (ed. P.C. Emson, M. Rossor and M. Tohyama), pp. 161-174. Elsevier: Amsterdam.

Bracha, H. S. (1987). Asymmetric rotational (circling) behavior, a dopamine-related asymmetry: preliminary findings in unmedicated and never-medicated schizophrenic patients. Biological Psychiarry 22, 995-1003.

Brown, R., Colter, N., Corsellis, J. A. N., Crow, T. J., Frith, C. D., Jagoe, R., Johnstone, E. C. \& Marsh, L. (1986). Postmortem evidence of structural brain changes in schizophrenia. Archives of General Psychiatry 43, 36-42.

Carruthers, R., Dawbarn, D., de Quidt, M., Emson, P. C., Hunter, J. \& Reynolds, G. P. (1984). Changes in the neuropeptide content of amygdala in schizophrenia. British Journal of Pharmacology 81, $190 \mathrm{P}$.

Clow, A., Theodorou, A., Jenner, P. \& Marsden, C. D. (1980) Changes in rat striatal dopamine turnover and receptor activity during one year's neuroleptic administration. European Journal of Pharmacology 63, 135-144.

Cross, A. J., Crow, T. J. \& Owen, F. (1979). Gamma-amino-butyric acid in the brain in schizophrenia. Lancet i, 560-561.

Crow, T. J., Owen, F., Cross, A. J., Ferrier, I. N., Johnstone, E. C., McCreadie, R. G., Owens, D. G. C. \& Poulter, M. (1981). Neurotransmitter enzymes and receptors in post-mortem brain in schizophrenia: evidence that an increase in D2 receptors is associated with the type I syndrome. In Transmitter Biochemistry of Human Brain Tissue (ed. P. Riederer and E. Usdin), pp. 8596. Macmillan: London.

Czudek, C. \& Reynolds, G. P. (1987). 3H-muscimol binding to postmortem brain tissue in schizophrenia. British Journal of Pharmacology 91, 342P.

Emrich, H. M., Zaudig, M., Kissling, W., Dirlich, G., von Zerssen, D. \& Herz, A. (1980). Des-tyrosyl- $\gamma$-endorphin in schizophrenia : a double-blind trial in 13 patients. Pharmacopsychiatry 13, 290298.

Farley, I. J., Price, K. S., McCullough, E., Deck, J. H. N., Hordyn- ski, W. \& Hornykiewicz, O. (1978). Norepinephrine in chronic paranoid schizophrenia : above-normal levels in limbic forebrain. Science 200, 456-458.

Ferrier, I. N., Roberts, G. W., Crow, T. J., Johnstone, E. C., Owens, D. G. C., Lee, Y. C., O'Shaughnessy, D., Adrian, T. E., Polak, J. M. \& Bloom, S. R. (1983). Reduced cholecystokinin-like and somatostatin-like immunoreactivity in limbic lobe is associated with negative symptoms in schizophrenia. Life Sciences 33, 475482.

Flor-Henry, P. (1969). Psychosis and temporal lobe epilepsy: a controlled investigation. Epilepsia 10, 363-395.

Hess, E. J., Bracha, H. S., Kleinman, J. E. \& Creese, I. (1987). Dopamine receptor subtype imbalance in schizophrenia. Life Sciences $40,1487-1497$.

Hornykiewicz, O. (1982). Brain catecholamines in schizophrenia - a good case for noradrenaline. Nature 299, 484-486.

Iversen, L. L., Reynolds, G. P. \& Snyder, S. H. (1983). Pathophysiology of schizophrenia-causal role for dopamine or noradrenaline? Nature 305, 377.

Jacob, H. \& Beckmann, H. (1986). Prenatal developmental disturbances in the limbic allocortex in schizophrenics. Journal of Neural Transmission 65, 303-326.

Joseph, M. H., Baker, H. F., Crow, T. J., Riley, G. J. \& Risby, D. (1979). Brain tryptophan metabolism in schizophrenia: a postmortem study of metabolism on the serotonin and kynurenine pathways in schizophrenic and control subjects. Psychopharmacology 62, 279-285.

Kleinman, J. E., Karoum, F., Rosenblatt, J., Gillin, J. C., Hong, J., Bridge, T. P., Zalcman, S., Storch, F., Delcarmen, R. \& Wyatt, R. J. (1981). Catecholamines and peptides in post-mortem schizophrenic brains. In Biological Psychiarry 1981 (ed. C. Perris, G. Struwe and B. Jannson), pp. 711-714. Elsevier: Amsterdam.

Kleinman, J. E., Iadorola, M., Govoni, S., Hong, J., Gillin, J. C. \& Wyatt, R. J. (1983). Post-mortem measurements of neuropeptides in human brain. Psychopharmacology Bulletin 19, 375-377.

Mackay, A. V. P., Iversen, L. L., Rossor, M., Spokes, E., Bird, E., Arregui, A., Creese, I. \& Snyder, S. H. (1982). Increased brain dopamine and dopamine receptors in schizophrenia. Archives of General Psychiatry 31, 991-997.

Memo, M., Kleinman, J. E. \& Hanbauer, I. (1983). Coupling of dopamine DI recognition sites with adenylate cyclase in nuclei accumbens and caudatus of schizophrenics. Science 221, 13041307.

Owen, F., Crow, T. J., Poulter, M., Cross, A. J., Longden, A. \& Riley, G. J. (1978). Increased dopamine-receptor sensitivity in schizophrenia. Lancet ii, 223-225.

Pimoule, C., Schoemaker, H., Reynolds, G. P. \& Langer, S. Z. (1985). (3H)SCH 23390 labelled D1 dopamine receptors are unchanged in schizophrenia and Parkinson's disease. European Journal of Pharmacology 11, 235-237.

Reynolds, G. P. (1983). Increased concentrations and lateral asymmetry of amygdala dopamine in schizophrenia. Nature 305, 527 529.

Reynolds, G. P. (1987). Postmortem neurochemical studies in 
schizophrenia. In Search for the Causes of Schizophrenia (ed. H. Haefner, W. F. Gattaz and W. Janzarik), pp. 236-240. Springer: Heidelberg.

Reynolds, G. P., Riederer, P., Jellinger, K. \& Gabriel, E. (1981). Dopamine receptors and schizophrenia: the neuroleptic drug problem. Neuropharmacology 20, 1319-1320.

Reynolds, G. P., Rossor, M. N. \& Iversen, L. L. (1983). Preliminary studies of human cortical 5-HT2 receptors and their involvement in schizophrenia and neuroleptic drug action. Journal of of Neural Transmission, Suppl. 18, 273-277.

Reynolds, G. P., Czudek, C., Bzowej, N. \& Seeman, P. (1987) Dopamine receptor asymmetry in schizophrenia. Lancet $\mathrm{i}, 979$.

Roberts, G. W., Ferrier, I. N., Lee, Y., Crow, T. J., Johnstone, E. C., Owens, D. G. C., Bacarese-Hamilton, A. J., McGregor, G. O'Shaughnessy, D., Polak, J. M. \& Bloom, S. R. (1983). Peptides, the limbic lobe and schizophrenia. Brain Research 288, 199-211.
Seeman, P., Ulpian, C., Bergeron, C., Riederer, P., Jellinger, K., Gabriel, E., Reynolds, G. P. \& Tourtellotte, W. W. (1984). Bimodal distribution of dopamine receptor densities in brains of schizophrenics. Science 225, 728-731.

Stein, L. \& Wise, C. D. (1971). Possible aetiology of schizophrenia: progressive damage to the noradrenergic reward system by 6hydroxydopamine. Science 171, 1032-1036.

Uhl, G. R. \& Kuhar, M. J. (1984). Chronic neuroleptic treatment enhances neurotensin receptor binding in human and rat substantia nigra. Nature 309, 350-352.

Whitaker, P. M., Crow, T. J. \& Ferrier, I. N. (1981). Tritiated LSD binding in frontal cortex in schizophrenia. Archives of General Psychiatry 38, 278-280.

Wise, C. D. \& Stein, L. (1973). Dopamine- $\beta$-hydroxylase deficits in the brains of schizophrenic patients. Science 181, 344-347. 